\title{
O Conceito de consciência em Vigotski: uma aproximação pela comparação de duas leituras
}

\author{
Cláudio Henrique Pedrosa \\ Núcleo da Abrapso em Goiânia - GO
}

\begin{abstract}
Resumo
Este trabalho apresenta uma comparação entre dois artigos que tratam da consciência na obra de Vigotski: "Conceito de consciência em Vigotski" e "A consciência na obra de L. S. Vigotski: análise do conceito e implicações para a psicologia e a educação", publicados respectivamente em 2006 e 2010, os quais destacam a importância de Vigotski na conceituação da consciência como objeto de uma psicologia que superasse sua crise paradigmática. Ao realizar uma comparação estrutural entre os dois textos, com recurso à crítica de leitor proposta por Vigotski em "Psicologia da Arte", este estudo constata a relevância dos dois trabalhos para o fortalecimento do campo teórico inaugurado pelo pensador soviético. Conclui-se com a proposta de uma reordenação lógica entre os dois textos que leve em conta o grau de complexidade e os arranjos internos de suas argumentações. Faz-se assim uma pequena contribuição à obra de Vigotski, amplamente utilizada na educação, porém pouco reconhecida na história da Psicologia.
\end{abstract}

Palavras-chaves: Vygotsky, consciência, história da Psicologia.

\section{The concept of consciousness in Vygotsky: an approximation by comparing two readings}

\begin{abstract}
This paper presents a comparison of two articles about the consciousness in the Vygotsky's work. The texts Conceito de consciência em Vigotski and A consciência na obra de L. S. Vigotsy: análise do conceito e implicações para a psicologia e a educação, published respectively in 2006 and 2010, emphasize the importance of Vygotsky to the concept of consciousness as the object of a psychology that would overcome its paradigm crisis. When performing a structural comparison between the two texts, by using the reader's criticism proposed by Vygotsky in "Psychology of Art", this study notes the importance of the two works to strengthen the theoretical field inaugurated by Vygotsky. We conclude by proposing a logical re-ordering between the two texts, taking into account the complexity and the internal arrangements of their arguments. It may be a small contribution to Vygotsky's work, widely used in education, but little recognized in the history of Psychology.
\end{abstract}

Keywords: Vygotsky, conscience, History of Psychology

\section{El concepto de conciencia en Vigotski: una aproximación mediante comparación de dos lecturas}

\begin{abstract}
Resumen
Este trabajo presenta una comparación entre dos artículos que tratan de la conciencia en la obra de Vigotski. Los textos Concepto de conciencia en Vigotski y La conciencia en la obra de L. S. Vigotski: análisis del concepto e implicaciones para la psicología y la educación, publicados respectivamente en 2006 y 2010, destacan la importancia de Vigotski en la conceptualización de la conciencia como objeto de una Psicología que supere su crisis paradigmática. Este estudio, al realizar una comparación estructural entre los dos textos recurriendo a la crítica de lector propuesta por Vigotski en "Psicología del Arte", constata la relevancia de los dos trabajos para el fortalecimiento del campo teórico inaugurado por Vigotski. Se concluye proponiendo una reordenación lógica entre los dos textos teniendo en cuenta el grado de complejidad y las disposiciones internas de sus argumentos. Así, se presenta una pequeña contribución a la obra de Vigotski ampliamente utilizada en la educación sin embargo poco reconocida en la historia de la Psicología.
\end{abstract}

Palabras Clave: Vigotski; conciencia; historia de la Psicología. 


\section{Introdução}

O objetivo específico deste texto é estabelecer uma discussão comparativa entre dois artigos em língua portuguesa que tratam do problema conceitual da consciência na obra de Vigotski, a saber, os artigos Conceito de consciência em Vigotski e A consciência na obra de L. S. Vigotski: análise do conceito e implicações para a psicologia e a educação, dos quais o primeiro é de autoria de Gisele Toassa (2007) e o segundo foi escrito por Lia Lordelo \& Robinson Tenório (2010). O objetivo geral que se pretende dessa discussão é contribuir com o campo dos estudos relativos à teoria de Vigotski, já amplamente conhecida como um instrumental valioso para o entendimento dos processos educacionais em torno dos quais a Psicologia vem sendo chamada a se pronunciar, mas ainda pouco reconhecida na História da Psicologia.

Não visamos aqui estabelecer uma comparação pueril ou ingênua, em termos de qual texto é o melhor ou de qual é mais recomendável, mas, antes, valorizar os dois trabaIhos, ordenando sua contribuição no campo histórico da Psicologia, tomando-os como ferramentas para ampliação das discussões ainda incipientes acerca da importância devida a L. S. Vigotski como historiador e como epistemólogo da Psicologia, conforme demonstrou Lordelo (2011). Tampouco é nosso objetivo instaurar um terceiro ponto de vista, mais amplo ou profundo, a partir do qual os dois trabalhos venham a ser julgados quanto à sua aproximação, em termos de precisão e acerto, do conceito mesmo de consciência na obra de Vigotski. Antes, estabelecemos os dois textos como parâmetros recíprocos, procurando avaliar seus consensos e suas discordâncias por meio de um diálogo entre ambos, aplicando - um pouco fora de lugar - aquilo que Vigotski chamou de "crítica de leitor" (Cf. Bezerra, 1999; Vigotski, 1999).

Ainda com esse mesmo espírito - um tanto deslocado e despojado de grandes pretensões - não tentaremos dissecar o contexto de produção dos dois textos ou analisar as implicações dos enunciados constitutivos dos textos. Ficarão de fora desta análise questões como: quem são os autores e autoras dos textos? Com quem dialogam nesses textos? Que vozes anteriores às suas estarão repercutindo? Que vozes estarão silenciando? Em que momento histórico suas ideias estão sendo expostas? Qual o peso institucional dos veículos em que essas ideias estão sendo postas em circulação?. Enfim, várias perguntas que poderiam conduzir a reflexões interessantes ficarão de fora deste trabalho, em parte pelo limite de tempo e espaço, em parte pela opção metodológica.

Para sermos fiéis a essa opção metodológica, seguiremos com Vigotski (1999) o mesmo método utilizado para abordar a Psicologia da obra de arte indo "da forma da obra de arte, passando pela análise funcional de seus elementos e da estrutura para a recriação da resposta estética". Ainda que não estejamos visando ao "estabelecimento de leis gerais" nesta análise comparativa, podemos adotar esse mesmo esquema "forma-estrutura-função" para gerar algum entendimento das obras acadêmicas.
É preciso reconhecer que o objeto de análise submetido por Vigotski à "crítica de leitor", a obra de arte, mantém suas especificidades, sobretudo no que concerne à finalidade estética e ao caráter ficcional, em contraste com a obra científica, que é produzida sob regras bastante distintas. Não obstante, em face de sólidas e recentes inquietações sobre as aproximações entre arte e ciência, interrogando-nos "Até que ponto a dimensão estética está presente e é importante na atividade dos cientistas" (Massarani, Moreira, \& Almeida, 2011 , p. 7), não consideramos totalmente impróprio o uso desse método de análise para estudar produções científicas, como o que tentamos nestas páginas.

Seguindo essa proposta, pretendemos nos deter primeiro na forma e função dos textos, consideradas aqui como uma disposição intencional do respectivo material argumentativo. Em seguida, queremos desenvolver uma reflexão em torno do efeito que cada um dos textos, por suas propriedades, poderia imprimir em um leitor, concebido não como um apreciador da estética, mas como um interessado no campo temático constituído pela Psicologia de Vigotski.

\section{A falta de consciência da Psicologia sobre a consciência em Vigotski}

Antes de nos determos na comparação, cabe uma breve observação sobre a importância do conceito de consciência para a Psicologia de Vigotski, e de modo mais dialético, sobre a importância da Psicologia de Vigotski para a sobrevivência do conceito de consciência no âmbito da Psicologia moderna.

Infelizmente, seria exagero falar em consenso geral, pois casos como o do Manual de Shcultz e Schultz (2006), que consegue realizar uma história da Psicologia moderna passando ao largo das contribuições de Vigotski, não são raros na "história" da História da Psicologia. Densas incursões pela epistemologia da Psicologia como as empreendidas por Figueiredo (2008) e Japiassu (2001) deixam de lado o projeto de Vigotski, que deveria ser tido como um ponto de inflexão, a julgar pelas leituras mais recentes da importância do psicólogo soviético como proponente de uma metodologia e de uma epistemologia para a Psicologia. Para Lia Lordelo (2011), embora tenha se tornado mais conhecido por suas contribuições conceituais para a Psicologia da Educação, "Vigotski deixou outro legado teórico importante, o qual diz respeito ao estudo da história da psicologia enquanto ciência e à crítica das ideias psicológicas em voga no início do século XX" (Lordelo, 2011, p. 537). Ademais, segundo observa a pesquisadora e educadora Zoia Prestes, falando do período entre 1925 e 1930, "os estudos do grupo liderado por Vigotski provocam uma revolução na interpretação da consciência como uma forma especial de organização do comportamento do homem" (Prestes, 2010, p. 31).

Apesar de ter sido negligenciado e jogado no ostracismo, o trabalho de Vigotski sobre a produção da consciência individual como um processo histórico e social, revestido de objetividade suficiente para suportar uma investigação 
científica, escapava ao mesmo tempo do reducionismo positivista e do racionalismo idealista - aspectos característicos das opções disponíveis à época os quais, segundo nos contam os historiadores da epistemologia da psicologia, ora a mantinham presa no campo das ciências naturais, ora se perdiam na estratosfera da especulação metafísica (Japiassu, 2001; Mariguela, 1999). Transpor esse dualismo e debruçar-se sobre a consciência como um fenômeno unitário e concreto representava um desafio. É ainda Zoia Prestes quem nos conta, seguindo declarações de Leontiev (citado por Prestes, 2010), que o desafio assumido pelo grupo "era penetrar nos estudos sobre a consciência como uma realidade própria da psicologia, desvendar a consciência como uma forma especificamente humana da psiquê e apresentar sua característica substancial." (Prestes, 2010, p.63).

Diante dessas observações sobre a força da contribuição teórico-metodológica de Vigotski e a contrastante ausência de referências à psicologia soviética posterior a Pavlov nos manuais de Psicologia Geral, é difícil resistir à tentação de formular uma afirmação irônica a respeito da falta de consciência da Psicologia acerca do conceito de consciência na Psicologia vigotskiana.

Feitas essas breves observações com a finalidade de destacar a importância do projeto de uma nova psicologia que visava ultrapassar as barreiras conceituais impostas pelo método tradicional e a relevância da consciência nesse projeto, tomada como um objeto concreto e perscrutável, ainda que complexo e dinâmico, passamos à exploração dos artigos já referidos.

\section{Vigotski e consciência: duas diferentes aproximações}

Por ordem cronológica, o artigo de Gisele Toassa, de 2006, veio a público antes do texto de Lia Lordelo e Robinson Tenório, publicado em 2010, num contexto que se caracteriza "pela escassez de trabalhos de natureza teórico-crítica sobre as reflexões produzidas por Vigotski, no âmbito da Psicologia enquanto ciência" (Lordelo \& Tenório, 2010, p. 80); contudo, ao contrário do que se poderia esperar, o segundo texto não faz qualquer referência ao primeiro.

Ao nos debruçarmos sobre os títulos, encontramos no primeiro uma estrutura sintética, quase lapidar, conceito de consciência em Vigotski (Toassa, 2006); e no segundo, a exposição um pouco mais detalhada de um compromisso ou de um interesse específico: A consciência na obra de L.S. Vigotski: análise do conceito e implicações para a Psicologia e a Educação.

O segundo texto, cujo título explicita um compromisso da reflexão teórica com as possibilidades de sua aplicação na prática, ou ao menos sua aplicação em campos de conhecimento (e prática?) específicos, faz um percurso demarcado pelos seguintes tópicos: Introdução, no qual se apresentam os objetivos, a justificativa e o percurso metodológico do texto; Transformação no conceito vigotskiano de consciência, no qual são analisadas as mudanças nos termos que fundamentam a proposições teóricas de Vigotski acerca da consciência, primeiro como construto mais intimamente ligado ao paradigma reflexológico, inaugurado por Pavlov e consolidado por Bekhterev (1923, citado por Vigotski, 2004), posteriormente voltado "para uma concepção semiótica ou mediacional” (Lordelo \& Tenorio, 2010, p. 81). Concepção mais evidentemente marcada por uma relação dialética entre a consciência e a experiência social. Em certa medida, essa dialética já poderia ser antevista no $A$ consciência como problema da psicologia do comportamento (Vigotski, 1925/2004).

O Tópico seguinte, no texto de Lordelo e Tenório (2010) A consciência no espelho: uma nova epistemologia para a psicologia discute a analogia proposta por Vigotski entre a relação da consciência com o mundo real e a relação da imagem refletida no espelho com o objeto real que dá origem à imagem. Em resumo, a consciência é como a imagem de um objeto no espelho, que não tem as mesmas qualidades do objeto, mas que tem qualidades próprias que nos permite afirmar sua existência objetiva. A imagem no espelho possui existência e realidade distintas do objeto, mas ainda assim está submetida a leis materiais. Assim também é a consciência. Nesse trecho Lordelo e Tenorio (2010) procuram chamar atenção para "os significados que a metáfora do espelho carrega no contexto das reflexões epistemológicas de Vigotski" (p. 83) implicando uma atenção aos condicionantes históricos da produção do conhecimento, e não somente aos condicionantes psicogenéticos.

Por fim, um último tópico deste texto (antes da Conclusão, na qual será reapresentado todo o percurso de modo mais sucinto), intitula-se Algumas implicações para a educação ou um outro Vigotski. Neste tópico Lordelo e Tenório destacam a recorrência do uso de Vigotski para legitimar um conjunto de problemas teóricos parciais, relacionados à linguagem, à resolução de problemas e à aprendizagem no âmbito da Psicologia e da educação escolar. Em contraste com esse uso, procuram deter-se sobre um Vigotski diferente. "Este pesquisador, sobre o qual nos debruçamos aqui, elaborou reflexões de cunho epistemológico e metodológico que amparam problemas atuais dentro das ciências humanas de modo geral e, mais especificamente, na psicologia e na pedagogia" (2010, p. 84) entretanto, recusa-se à tarefa de extrair da reflexão apresentada "orientações sobre como agir numa situação específica, por exemplo, em sala de aula." (Lordelo e Tenório, 2010, p. 84), busca aproximações via marxismo entre Vigotski e Paulo Freire e enuncia "algumas reflexões das quais a educação possa se beneficiar" (2010, p. 84.). em torno da prática de ensino e da escola como espaços historicamente privilegiados para desenvolvimento da consciência. Em seguida vem a Conclusão, que, como já dissemos, sintetiza o texto e reapresenta as implicações do trabalho de Vigotski para o campo da Educação e da Psicologia.

O texto de Toassa não é tão sintético, nem tão fácil de seguir, não só pela ausência nele de tópicos ou subtítulos que demarquem sua estrutura, mas também pela presença de índices e referências de uma leitura histórica mais de- 
talhada e por um mergulho mais profundo na estrutura do conceito de consciência. Podemos dizer que a densidade dos textos é inversa à simplicidade dos seus títulos.

Enquanto o texto de Lordelo e Tenório se detém sobre um aspecto interno das modificações do conceito de consciência na teoria de Vigotski, numa espécie de desenvolvimento "psicogenético" do conceito em Vigotski, o texto anterior, de Toassa, procura compreender esse desenvolvimento em termos de uma gênese sócio-histórica. Nessa perspectiva, Vigotski não só é apresentado como sujeito a condições históricas específicas, mas principalmente é visto como sujeito de transformações históricas:

Leningrado, II Congresso Nacional de Psiconeurologia, 6 de janeiro de 1924. Um recém-chegado da Bielo-Rússia apresenta a comunicação intitulada "Os métodos de investigação reflexológicos e psicológicos" (...)

O texto apresentado [no II Congresso] demarca a primeira posição de Vigotski no campo metodológico, já imersa num debate que se revelaria crucial para o desenvolvimento de seu enfoque: o introspeccionismo subjetivista versus a ciência dos reflexos, objetivista; a psicologia é ferramenta de uma sociedade que se reconstrói na luta de forças revolucionárias e contra-revolucionárias. A nova ciência ganha conotações político-ideológicas e se expande dos laboratórios experimentais para as aplicações sociais. (Toassa, 2006, p. 60-61)

Outro aspecto relativo às formas dos dois textos comparados é que em Toassa (2006) verificamos uma tendência mais analítica, explorando o conceito de consciência em seus elementos fundamentais, ao passo que Lordelo e Tenório (2010) optam por uma forma mais condensada ou sintética, explorando aspectos gerais da proposta conceitual de Vigotski.

Mesmo destoantes no grau de detalhamento ou de profundidade da descrição, ambos referem-se à importância do papel protagonizado por Vigotski e a psicologia sócio-histórica no cenário da psicologia russa; e, se tradicionalmente tem sido negligenciado o compromisso de Vigotski com o socialismo, sobretudo em algumas traduções de suas obras, como demonstrou Zoia Prestes (2010), com os textos discutidos aqui isso não ocorreu. Ambos posicionam Vigotski explicitamente no campo do marxismo, enfatizando seu compromisso com o modo de produção socialista: "Vigotski é um autor marxista conquanto muito distante de extrações deterministas do marxismo, como aquelas de Stálin ou Kautsky. Suas falas são pesadas na crítica à forma de vida burguesa e entusiástica no planejamento de uma sociedade socialista" (Toassa, 2006, p. 80). A isso complementam Lordelo e Tenório, buscando associá-los ao teórico marxista Paulo Freire: "Embora não devamos equivaler o conceito de consciência psicológica (tal qual proposto por Vigotski) ao de consciência crítica de Freire, há, pelo menos, uma influência em comum a ambos os autores: o marxismo" (2010, p. 84). Ambos os textos sugerem o marxismo como um fator co- mum em vista do qual o conceito de consciência torna-se tão importante, embora Toassa não estabeleça comparações entre a consciência freireana e a consciência em Vigotski.

Ambos também apontam a proximidade inicial que Vigotski manteve com o campo da reflexologia, no estudo da consciência. Primeiro Toassa afirma que "é com a terminologia da ciência dos reflexos que ele sintetiza algumas de suas primeiras ideias sobre a consciência, linguagem e inconsciente" (Toassa, 2006, p. 62), e depois, Lordelo e Tenório reafirmam: "Utilizando a linguagem da corrente que criticava, ele define a consciência como "um mecanismo de transmissão entre sistemas de reflexos'” (Lordelo \& Tenório, 2010 , p. 81 , grifos nossos). Mais adiante acrescentam: “(...) o mecanismo através do qual ele propõe que se estude a consciência é tão reflexológico quanto o do estudo de um comportamento qualquer." (Lordelo \& Tenório, 2010, p. 81)

Enquanto neste texto Lordelo e Tenório enfatizam a metáfora do espelho e sua implicação para uma epistemologia da consciência, no texto anterior, de Toassa, a via da análise histórica resulta numa apreensão da consciência em três sentidos específicos: um relativo à tomada de consciência da realidade externa e interna - implicado com o domínio das formas semióticas de mediações cognitivas e afetivas, incluindo a autopercepção ou a tomada de consciência do "eu"; um sentido relacionado à consciência como atributo dos conteúdos ou dos fenômenos psíquicos; e o sentido da consciência como sistema psicológico. (Toassa, 2006, pp.72-78).

\section{A cisão do espelho: materialidade da consciência ou reflexo do real?}

Talvez seja neste ponto que se encontre a maior divergência entre os dois textos. Se antes a relação entre os dois poderia ser de concordância, ou de lacunas de aprofundamento, aqui se estabelece um claro distanciamento. Esse distanciamento aparece na medida em que, segundo Toassa, a metáfora da consciência como um reflexo no espelho é insuficiente para representar a complexidade do processo de conscientização em Vigotski.

(...) o processo de criação de um sentido, de uma interpretação para o mundo e suas relações já seria uma forma de criação de novas combinações: não é a realidade que simplesmente "se reflete" na consciência, mas também o indivíduo que a reconstitui ativamente e nela interfere, produzindo uma nova versão da realidade externa e das próprias vivências representadas na palavra. Diferentemente de outras teorias da Psicologia, o sistema da consciência para o autor não equivale à percepção, (...).(Toassa, 2006, p.72-73)

Claro que uma leitura cuidadosa de Lordelo e Tenório (2010) vai nos colocar diante de uma série de ressalvas sobre os riscos de limitação acarretados pelo uso de metáforas. Vemos também uma perspectiva a respeito da metá- 
fora do espelho, em que esta serviria apenas para ilustrar o reconhecimento da natureza ou de uma realidade específica e material da consciência, em sentido contrário à suposição de sua imaterialidade.

Podemos dizer que o uso da analogia com o espelho intenta simplesmente destacar sua realidade material, e não apresentar a consciência como estático espelho da natureza. Se isso acontece, é apenas como resíduo ou efeito colateral; mas é com a eliminação desses resíduos que o texto de Toassa (2006) parece comprometido, quando rejeita a ideia de "consciência" como imagem projetada passivamente no cérebro. "O caráter voluntário e criativo da atividade cerebral permite, assim, dizer que a realidade reflete-se não apenas no, mas também pelo cérebro." (p.78, grifo no original). Acrescenta o autor: "Este processo desenvolve-se graças à mediação da experiência acumulada e sintetizada na linguagem" (idem). É a linguagem (que Zoia traduziu por fala), em seu diálogo intenso com o pensamento, que vai constituir a consciência como uma faculdade tão genuinamente humana.

\section{Conclusão}

Enfim, trata-se aqui de um par de textos com algumas concordâncias e diferenças significativas, marcadas não só pelo número de páginas (25 e 8) - o que pode ser entendido como efeito de formatação - mas, sobretudo, pelo peso ou densidade com que cada um aporta no campo de discussão, com que cada um contribui para o entendimento da consciência como um objeto psicológico e para a consolidação da psicologia sócio-histórica.

O primeiro texto (Toassa, 2006) reflete uma postura mais atenta aos meandros históricos que emolduram o surgimento da psicologia de Vigotski e, nela a formulação do conceito de consciência. O segundo (Lordelo \& Tenório, 2010), mesmo não possuindo a densidade formal do primeiro, reúne material suficiente para compor uma significativa contribuição ao campo. A sistematização em tópicos e a expressão de uma limitada cobertura do campo (denunciada pela omissão de um texto similar publicado anteriormente) tornam esse texto mais indicado para um leitor iniciante, cuja zona de desenvolvimento atual ainda esteja relativamente restrita. Por outro lado, a recuperação do plano histórico, o aprofundamento da análise conceitual, a transcendência da consciência como representação estática, são aspectos que colocam o texto de Toassa como recurso de desenvolvimento mais apropriado para interlocutores com maior domínio das questões relativas campo teórico em estudo.

Não obstante, é defensável que a leitura de ambos os textos seja indicada para qualquer leitor, de nível avançado ou não, pois mesmo o texto mais complexo pode funcionar como motor do desenvolvimento, em termos equivalentes aos da zona de desenvolvimento próximo; contudo, a despeito da cronologia dos textos, uma análise do tempo lógico - ou seja, da ordem de encadeamento de seus argumentos e razões (Goldschimit, 1968) - faz crer que os textos seriam mais bem aproveitados se lidos em ordem inversa à cronologia de sua publicação.

\section{Referência bibliográfica}

Bezerra, P. (1999). Um crítico muito original. Em L. Vigotski, A tragédia de Hamlet, Príncipe da Dinamarca (pp. ix-xv). São Paulo: Martins Fontes.

Figueiredo, L. C. (2008). Matrizes do Pensamento Psicológico (14a ed.). São Paulo: Vozes.

Goldschmidt, V. (1968) Tempo histórico e tempo lógico na interpretação dos sistemas filosóficos. Em V. Goldschmidt, A religião de Platão (pp.139-147). São Paulo: Difusão Européia do Livro.

Japiassu, H. A. (2001). Emergência da Psicologia Científica. Em H. A. Japiassu, Introdução à Epistemologia da Psicologia (6a ed., pp.2143). São Paulo: Letras \& Letras.

Lordelo, L. (2011). A crise na psicologia: análise da contribuição histórica e epistemológica de L. S. Vigotski. Psic.: teor. pesq., 27(4), 537-544.

Lordelo, L., \& Tenorio, R. (2010). A consciência na obra de L. S. Vigotski: análise do conceito e implicações para a psicologia e a educação. Psicol. esc. educ., 14(1), 79-86. Recuperado: $05 \mathrm{dez}$ 2011. Disponível: http://www.scielo.br/pdf/pee/v14n1/v14n1a09. pdf

Mariguela, M. (1995). Epistemologia da Psicologia. Piracicaba, SP: Unimep,

Massarani, L., Moreira, I. de C., \& Almeida, C. (2006). Para que um diálogo entre ciência e arte?. Hist. cienc. saúde - Manguinhos, 13, 7-10. Recuperado: 13 dez 2011. Disponível: http://www.scielo.br/ $\mathrm{pdf} / \mathrm{hcsm} / \mathrm{v} 13 \mathrm{~s} 0 / 00 . \mathrm{pdf}$

Prestes, Z. (2010). Quando não é quase a mesma coisa. Análise de traduções de Lev Semionovitch Vigotski no Brasil: repercussões no campo educacional. Tese de Doutorado, Faculdade de Educação, Universidade de Brasília, Brasília-DF.

Schultz, D., \& Schutz, S. (2006). História da Psicologia Moderna. São Paulo: Thomson,

Toassa, G. (2006). Conceito de consciência em Vigotski. Psicol. Usp, 17(2). Recuperado: 12 dez 2011. Disponível: http://www.scielo.br/ pdf/pusp/v17n2/v17n2a04.pdf

Vigotski, L. S. (2001). Psicologia da Arte. São Paulo: Martins Fontes .

Vigotski, L. S. (2004). A consciência como problema da psicologia do comportamento. Em L. S. Vigotski: Teoria e método em Psicologia (pp. 55-85). São Paulo: Martins Fontes. 
Recebido em: 19-04-2012

Aprovado em: 06-08-2012

\section{Sobre o autor}

Cláudio Henrique Pedrosa (c.h.pedrosa@gmail.com.br)

Mestre em Psicologia Social pela PUC/SP

Núcleo Abrapso de Goiânia.

Endereço: Rua R-03, Quadra 02; Lote 25. - Vila Itatiaia, Goiânia - GO, CEP: 74260-690. 